\author{
G. Siciliano \\ S. Piazza \\ C. Carlesi \\ A. Del Corona \\ M. Franzini \\ A. Pompella \\ G. Malvaldi \\ M. Mancuso \\ A. Paolicchi \\ L. Murri
}

\title{
Antioxidant capacity and protein oxidation in cerebrospinal fluid of amyotrophic lateral sclerosis
}

Abstract Background The causes of Amyotrophic Lateral Sclerosis (ALS) are unknown. A bulk of evidence supports the hypothesis that oxidative stress and mitochondrial dysfunction can be implicated in ALS pathogenesis. Methods We assessed, in cerebrospinal fluid (CSF) and in plasma of 49 ALS patients and 8 controls, the amount of oxidized proteins (AOPP, advanced oxidation protein products), the total antioxidant capacity (FRA, the ferric reducing ability), and, in CSF, two oxidation products, the 4-hydroxynonenal and the sum of nitrites plus nitrates. Results The FRA was decreased $(p=0.003)$ in $\mathrm{CSF}$, and AOPP were increased in both CSF $(\mathrm{p}=0.0039)$ and plasma $(\mathrm{p}=0.001)$ of ALS patients. The content of AOPP was differently represented in CSF of ALS clinical subsets, resulting in increase in the common and pseudopolyneuropathic forms $(\mathrm{p}<0.001)$ and nearly undetectable in the bulbar form, as in controls. The sum of nitrites plus nitrates and 4-hydroxynonenal were unchanged in ALS patients compared with controls. Conclusion Our results, while confirming the occurrence of oxidative stress in ALS, indicate how its effects can be stratified and therefore implicated differently in the pathogenesis of different clinical forms of ALS.

Key words amyotrophic lateral sclerosis - oxidative stress · cerebrospinal fluid

\section{Introduction}

Amyotrophic Lateral Sclerosis (ALS) is a degenerative disease of unknown origin characterized by the progressive loss of motor neurons of the anterior horns in the spinal cord, bulb and cortex. Among the several pathogenetic mechanisms considered in an attempt to explain motor neuron death in ALS, the hypothesis of the occurrence of oxidative stress has recently received considerable interest. The first suggestion of a possible role of the involvement of reactive oxygen species production mechanisms in this disease de- rives from the observation that mutations in the copper/zinc superoxide dismutase-1 (SOD-1) gene are responsible for approximately $20 \%$ of familial ALS (fALS) cases, mainly inherited with an autosomal dominant trait $[4,19]$.

A bulk of evidence supports the oxidative stress hypothesis also in sporadic ALS (sALS). Studies on post-mortem tissues from sALS patients provided evidence of accumulation of oxidative damage to proteins, lipids, or DNA $[3,26]$. Biochemical markers of oxidative stress such as malondialdehyde and 8 -hydroxy-2-deoxyguanosine $[12,27,28]$ were found to be increased in sALS patients compared with 
normal subjects. Related to that, a number of studies have suggested a potential role of mitochondrial dysfunction as responsible for increased production of reactive oxygen species in ALS. Multiple respiratory chain enzyme deficiencies have been reported in skeletal muscle of ALS patients [30,33]. Further a decrease in cytochrome $c$ oxidase activity has also been observed in motor neurons in patients with sALS [10].

The aim of the present study has been to further contribute to the understanding of what extent there is involvement of oxidative stress in ALS and in its different clinical forms. To do that we have assessed some markers of oxidative stress in cerebrospinal fluid (CSF) and in plasma of ALS patients and controls.

\section{Patients and Methods}

\section{Patients}

The study included 49 patients, 31 males and 18 females, mean age $62.73 \pm$ SD 10.82-years. ALS diagnosis was made on the basis of the revised El Escorial criteria [8]. Four cases were affected by fALS, with G46S SOD1 mutation. Ten patients presented with the bulbar form of disease, twenty-one the classic form and the remaining cases progressive muscular atrophy. The control group was represented by 8 subjects, 5 males and 3 females, mean age $41.25 \pm S D$ 14.64-years, with neurological diseases other than ALS (six with sensory-motor peripheral neuropathy, one with probable multiple sclerosis and one with cerebral vasculitis), with a comparable degree of motor impairment as judged on the basis of the Appel score (AS) functional rating scale at the time of the study and without detectable CSF or plasma abnormalities at standard laboratory analysis. The AS functional rating scale includes assessment of swallowing, speech and respiratory function, and both strength and function of upper and lower extremity musculature [5]. The difficulty in getting CSF samples without laboratory abnormalities justified the limited numbers of controls involved in our study. In all ALS patients CSF standard laboratory examination did not show alteration in cell counts, ors in total amount of protein, and no oligoclonal bands were found.

Both the control and ALS groups habitually followed a dietary regimen of Mediterranean type, this mainly being characterized by high intake of vegetables, legumes, fruits, cereals and unsaturated fats, particularly olive oil, and low to moderate intake of dairy products. The smoking habits also did not differ between the two groups, participating subjects mainly being non smokers. None of the patients or controls was taking medications with antioxidant properties. CSF samples, basically collected in an early stage of disease $(8.35 \pm 12.7$ months from the beginning of the disease, range: 1-24), were taken by lumbar puncture. Approximately 6-8 $\mathrm{ml}$ of CSF were collected in polypropylene tubes for diagnostic purposes. The samples were split into $1 \mathrm{ml}$ aliquots and stored at $-80^{\circ} \mathrm{C}$ prior to use. Eight $\mathrm{ml}$ of blood sample was drawn from antecubital veins into Vacutainer tubes, centrifuged to eliminate cells and other insoluble material, and the excess was stored in $1 \mathrm{ml}$ aliquots at $-80^{\circ} \mathrm{C}$. The days elapsed between sample collection and analysis defined the sample storage time (28.78 \pm 16.15 months).

All subjects gave their informed consent after the purpose of study had been explained to them.

\section{Methods}

\section{Advanced oxidation protein products}

Advanced oxidation protein products (AOPP) stable marker of oxidative damage to proteins, were determined according to WitkoSarsat et al. [34]. Briefly: CSF or plasma were mixed with $\mathrm{H}_{2} \mathrm{O}$, acetic acid and potassium iodide. The absorbance was read spectrophotometrically at $340 \mathrm{~nm}$ and compared with a solution of chloramine $\mathrm{T}$ dissolved in the same buffer. The data were expressed as (mol/l of chloramine equivalents and related to CSF or plasma total protein, albumin, and immunoglobulin concentration.

\section{Ferric reducing ability}

In order to measure non enzymatic anti-oxidant properties, ferric reducing ability (FRA) was assessed according to Benzie et al. [9]. Briefly: the FRA reagent (sodium-acetate, tripiridiltriazyne in hydrochloric acid and ferric chloride) pre-warmed to 37(C were mixed with CSF or plasma; the absorbance was read after $3 \mathrm{~min}$. at $593 \mathrm{~nm}$. A calibration curve was established by substituting the sample with a solution of iron sulphate in hydrochloric acid.

\section{4-hydroxynonenal}

4-HNE 4-hydroxynonenal (4-HNE) is a highly reactive but relatively stable end product of oxidative degradation of arachidonic acid and linoleic acid and its effect is concentration dependent.

Protein bound 4-Hydroxynonenal (HNE) was revealed in western blots of CSF proteins in all the 8 patients and in controls by a rabbit polyclonal antibody obtained by immunizing rats with keyhole-limpet hemocyanin-4-HNE adducts. Immunoreactive bands were revealed by enhanced chemiluminescence, and the intensity of the bands was semi-quantitated by a Bio-Rad (Milano) [23].

Nitrites + nitrates assay

Nitrites and nitrates represent the stable end products of reaction between nitric oxide and superoxide via peroxynitrite which then decomposes rapidly to them $[6,23]$. We determined the sum of nitrites plus nitrates in 27 patients and in all controls, by the nitric oxide quantitative kit (Active Motif, Firenze). Nitric oxide assay is performed using a two-steps assay. The first step is the reduction of nitrate into nitrite by nitrate reductase. In the final step, Griess Reagent converts the nitrite into a purple-colored azo compound, which is quantitated by spectrophotometer at $\mathrm{A}_{450}$ [16].

\section{Statistical analysis}

In comparing the groups, we have assembled a Gaussian distribution of data, by using Student's t test for unpaired data. Variance analysis was performed by ANOVA, followed by the Neuman-Keuls test for multiple comparisons.

\section{Results}

\section{Advanced oxidation protein products}

CSF: AOPP were found to be significantly increased in CSF of ALS patients compared with controls $($ Mean $\pm \mathrm{SE}=13.2 \pm 1.7(\mathrm{~mol} / \mathrm{l}$, vs $0.75 \pm 0.55(\mathrm{~mol} /$ 


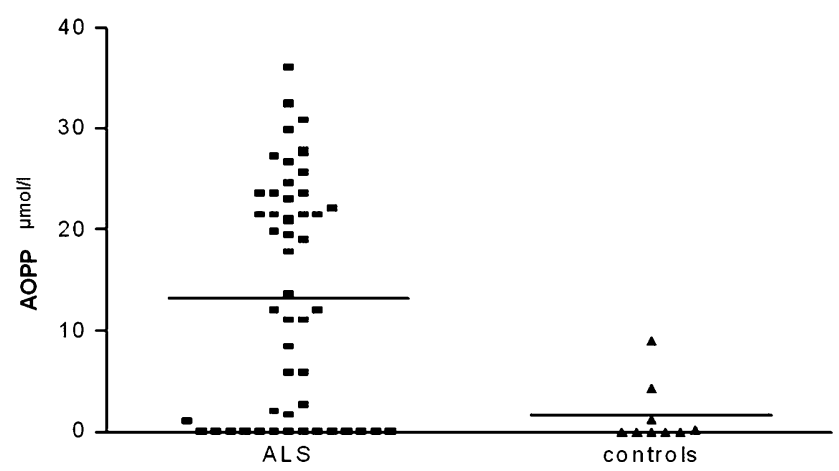

Fig. 1 values of AOPP in CSF of ALS patients and controls (difference significant for $p=0.003$ )

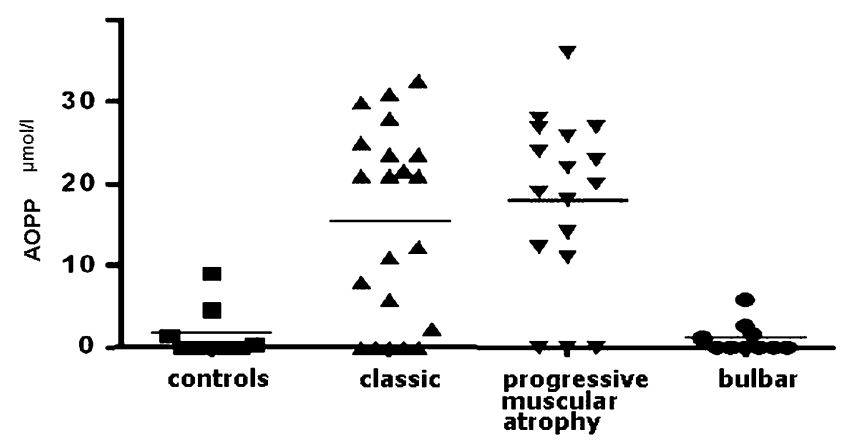

Fig. 2 CSF values of AOPP in the clinical subsets of ALS (difference significant for $p<0.001$ in the comparison between controls or bulbar forms and classic or progressive muscular atrophy)

$1, p=0.0039$ ) [Fig. 1]. When the different clinical forms of ALS were considered separately, patients with the classical form $(15.35 \pm 2.47(\mathrm{~mol} / \mathrm{l})$ or the pseudopolyneuropathic form (18.02 \pm 2.57 (mol/l) still maintained significantly higher values of AOPP $(p<0.001)$, while no difference was observed between patients with the bulbar form $(1.1 \pm 0.59(\mathrm{~mol} /$ 1) and controls [Fig. 2].

Plasma: AOPP were found to be significantly increased in plasma of ALS patients compared with controls (Mean $\pm \mathrm{SE}=286.93 \pm 110.12(\mathrm{~mol} / \mathrm{l}$, vs $135.38 \pm 77.83$ (mol/l, $\mathrm{p}=0.001)$ [Fig. 3]. No difference was found between AOPP in different clinical forms of ALS.

No correlation between AOPP and total protein content was found in CSF of ALS patients and controls.

\section{Ferric reducing ability}

CSF: FRA was found to be significantly decreased in CSF of ALS patients compared with controls $(48.8 \pm 2.2(\mathrm{~mol} / \mathrm{l}$ vs $61.3 \pm 3.2(\mathrm{~mol} / \mathrm{l}, \mathrm{p}=0.003)$ [Fig. 4], but no difference was found when comparing

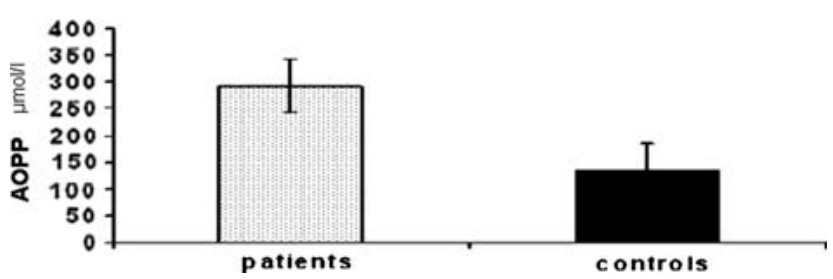

Fig. 3 plasmatic AOPP values of ALS patients and controls (difference significant for $p=0.001$ )

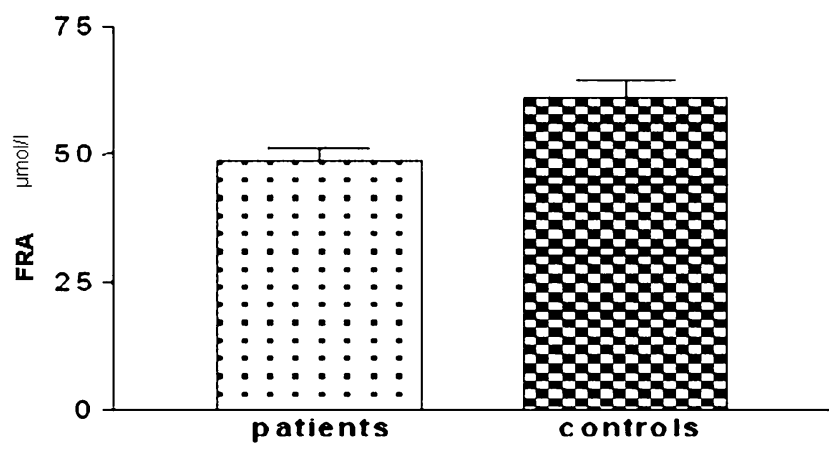

Fig. 4 values of FRA in CSF of ALS patients and controls (difference significant for $p=0.003$ )

the three clinical subsets of the disease with each other.

Plasma: No difference was found between ALS patients and controls or between the three clinical subsets of the disease.

No correlation between values of either AOPP or FRA and duration/severity of illness or sample storage time was observed.

\section{Protein-bound 4-hydroxynonenal}

Most of the immunoreactive 4-HNE was found to be associated with a $60 \mathrm{KDa}$ band, probably corresponding to albumin; however several additional bands with higher molecular weight were also detected. Immunoreactivity was stronger in ALS patients than in controls. However, when quantified, the difference did not reach a statistical significance level (data not shown).

\section{Nitrites + nitrates assay}

Comparable values of the sum [nitrite + nitrate] were found in 27 examined ALS patients and in controls $(6.37 \pm 0.72(\mathrm{~mol} / \mathrm{l}$ vs $6.71 \pm 1.06(\mathrm{~mol} / \mathrm{l}, \mathrm{p}=\mathrm{NS})$. Further, the nitrites values of the two controls affected by multiple sclerosis and vasculitis were similar to those of the other six controls. No difference was found between the different forms of ALS. 


\section{Discussion}

Oxidative stress is considered one of the most challenging pathogenetic hypotheses in ALS. This possible role is emphasized by reports that underline its interconnection with other pathogenetic mechanisms in ALS such as deranged neuron glutamate metabolism [6] or protein aggregation [25]. Related to this, the main result of this study is represented by, rather than the finding of increased protein oxidation, a CSFconfined involvement of non-enzymatic antioxidant system in ALS patients. However, the different clinical subsets of patients show different alteration in some of the parameters analyzed. This suggests that oxidative stress may not always be a disease determinant in ALS, but rather variously involved in its different clinical forms. This was observed for the advanced oxidation protein products, while ferric reducing ability was uniformly reduced in CSF of our patients.

Our study reveals that CSF and plasma protein oxidation clearly occur in ALS patients. We found that in ALS patients, significantly as compared to controls, the total antioxidant capacity (FRA) was decreased in CSF, while the content of oxidized proteins (AOPP) was increased in both CSF and plasma. In addition, when considering separately different clinical forms of ALS, CSF increase of AOPP was present in patients with the common form and the progressive muscular atrophy form, but not in those with the bulbar form.

Plasma AOPP are related to dityrosine, a marker of oxidative damage to proteins [15], and are present in plasma, in two distinct forms, 670 and $70 \mathrm{kDa}$ in molecular weight, corresponding respectively to albumin aggregates and albumin monomeric form [34]. Increase in plasma AOPP occurs in diabetes and in renal failure. The AOPP values in our patients do not appear to reflect CSF protein profile, therefore suggesting that proteins other than albumins contribute to this product. Other studies could be useful to clarify that.

The FRA test measures the combined effect of the non-enzymatic antioxidants, providing an index of ability to prevent oxidative damage. In fact, biological fluids contain several antioxidants, including not only the well known antioxidant proteins, but also substances such as bilirubin, uric acid, albumin, tocopherol and ascorbic acid whose modest reducing potential is balanced by their elevated concentration $[13,14]$. In comparing CSF and plasma AOPP with FRA results, while the increase of oxidised protein level is observed in both CSF and plasma, the reduction of antioxidant capacity assessed by FRA is limited to the intrathecal compartment. This, resulting either from an excessive consumption of antiox- idants or, more interesting, from an intrinsic deficiency of factors concurring to FRA level, indicates a wider exposure of central nervous system to oxidative damage in ALS. According to the latter possibility, the reports on genetic susceptibility of ALS patients to some oxidative stress and mitochondrial function impairment have to be mentioned [18].

The fact that 4-HNE was found in all our ALS patients suggests that lipid peroxidation occurs in the CNS of ALS patients. 4-HNE is a potential causative molecule in neuronal damage. It modifies the affinity of $\mathrm{Na}^{+}$-dependent glutamate transporters type 2 (EAAT2) for glutamate, thus reducing EAAT2 capacity to remove this amino-acid from the synaptic wall [35]. An increase of 4-HNE in the CSF of ALS patients [1,2] has already been shown. Absence of significant difference compared with controls may be ascribed to the early stage of the disease, as previously reported $[28,29]$.

Peroxynitrites derive by the reaction of nitric oxide (NO) and superoxide anion radical. In the nucleus peroxynitrite causes impaired ATP utilization, DNA instability and cell death [36]. In addiction, nitric oxide can be converted, in mitochondria, in peroxynitrite which inactivates mitochondrial respiratory chain proteins [24], Mn-SOD [17] and mitochondrial permeability transition pore (MPTP), leading to mitochondrial calcium efflux $[20,21]$, a pro-apoptosis step [32]. Even if other studies [7] suggested that NO, through peroxynitrite production, might be a causative molecule of motor neuron death in ALS, our data seem not to corroborate the role of nitrosylation in ALS.

Interestingly, when the different clinical presentations of ALS were compared with each other, CSF oxidized protein level was elevated only in patients with classic or pseudopolyneuropathic form of the disease, while patients with bulbar form did not differ from controls. The reason for this difference is not clear. In ALS bulbar motor neurons are known to be particularly susceptible to some cell damage mechanism, partly related to oxidative stress as is the case of the reported reduced expression of the antioxidant enzyme Mn-SOD [31]. Therefore it is possible that intrinsic differences between spinal and bulbar motor neurons can explain their selective vulnerability to various oxidative stress mechanisms.

In conclusion, in conjunction with the abovementioned evidence of the effects of reactive oxygen species on protein oxidation, the present study emphasizes the importance of a better understanding of the precise role of oxidative stress in the pathogenesis of ALS.

Acknowledgements: The authors are grateful to Dr. Anna Choub for her critical reading of the manuscript. 


\section{References}

1. Abe $\mathrm{T}$, Tohgi $\mathrm{H}$, Isobe $\mathrm{C}$, Murata $\mathrm{T}$, Sato C (2002) Remarkable increase in the concentration of 8-hydroxyguanosine in cerebrospinal fluid from patients with Alzheimer's disease. J Neurosci Res 70:447-450

2. Abe T, Isobe $C$, Murata T, Sato C, Tohgi $\mathrm{H}$ (2003) Alteration of 8-hydroxyguanosine concentrations in the cerebrospinal fluid and serum from patients with Parkinson's disease. Neurosci Lett 336:105-108

3. Agar J, Durham H (2003) Relevance of oxidative injury in the pathogenesis of motor neuron diseases. Amyotroph Lateral Scler Other Motor Neuron Disord 4:232-242

4. Andersen PM, Sims KB, Xin WW, Kiely R, O’Neill G, Ravits J, Pioro E, Harati Y, Brower RD, Levine JS, Heinicke HU, Seltzer W, Boss M, Brown RH Jr (2003) Sixteen mutations in the $\mathrm{Cu} / \mathrm{Zn}$ superoxide dismutase gene in Amyotrophic lateral sclerosis: a decade of discoveries, defects and disputes. Amyotroph Lateral Scler Other Motor Neuron Disord 4:62-73

5. Appel V, Stewart SS, Smith G, Appel SH (1987) A rating scale for amyotrophic lateral sclerosis: description and preliminary experience. Ann Neurol 22:328-333

6. Bär PR (2000) Motor neuron disease in vitro: the use of cultured motor neurons to study amyotrophic lateral sclerosis. Eur J Pharmacol 405:285-295

7. Beckman JS, Carson M, Smith CD, Koppenol WH (1993) ALS, SOD and peroxynitrite. Nature 364:584

8. Belsh JM (2000) ALS diagnostic criteria of El Escorial revisited: do they meet the needs of clinicians as well as researchers? Amyotroph Lateral Scler Other Motor Neuron Disord 1:57-60

9. Benzie IF, Strain JJ (1996) The Ferric Reducing Ability of Plasma (FRAP) as a measure of "Antioxidant Power": the FRAP assay. Anal Biochem 239:70-76.ù

10. Borthwick GM, Johnson MA, Ince PG, Shaw PJ, Turnbull DM (1999) Mitochondrial enzyme activity in amyotrophic lateral sclerosis, implications for the role of mitochondria in neuronal cell death. Ann Neurol 46:787-790

11. Esterbauer H, Schaur RJ, Zollner $H$ (1991) Chemistry and biochemistry of 4-hydroxynonenal, malonaldehyde and related aldehydes. Free Radic Biol Med 11:81-128

12. Fitzmaurice PS, Shaw IC, Kleiner HE, Miller RT, Monks TJ, Lau SS, Mitchell JD, Lynch PG (1996) Evidence for DNA damage in amyotrophic lateral sclerosis. Muscle Nerve 19:797-798
13. Gutteridge JM (1995) Lipid peroxidation and antioxidants as biomarkers of tissue damage. Clin Chem 41:18191828

14. Halliwell B, Gutteridge JM (1995) The definition and measurement of antioxidants in biological systems. Free Radic Biol Med 18:125-126

15. Heinecke JW, Li W, Daehnke HD, Goldstein JA (1993) Dityrosine, a specific marker of oxidation, in synthesized by the myeloperoxidasehydrogen peroxide system of human neutrophils and macrophages. J Biol Chem 268:4069-4077

16. Huang LE, Willmore WG, Gu J, Goldberg MA, Bunn HF (1999) Inhibition of hypoxia-inducible factor 1 activation by carbon monoxide and nitric oxide. Implications for oxygen sensing and signaling. J Biol Chem 26:9038-44

17. MacMillan-Crow LA, Crow JP, Kerby JD, Beckman JS, Thompson JA (1996) Nitration and inactivation of manganese superoxide dismutase in chronic rejection of human renal allograft. Proc Natl Acad Sci USA 93:11853-11858

18. Mancuso M, Conforti FL, Rocchi A, Tessitore A, Muglia M, Tedeschi G, Panza D, Monsurro M, Sola P, Mandrioli J, Choub A, DelCorona A, Manca ML, Mazzei R, Sprovieri T, Filosto M, Salviati A, Valentino P, Bono F, Caracciolo M, Simone IL, La Bella V, Majorana G, Siciliano G, Murri L, Quattrone A (2004) Could mitochondrial haplogroups play a role in sporadic amyotrophic lateral sclerosis? Neurosci Lett 371:158-162

19. Orrell RW (2000) Amyotrophic lateral sclerosis: copper/zinc superoxide dismutase (SOD-1) gene mutations. Neuromuscul Disord 10:63-68

20. Packer MA, Murphy MP (1994) Peroxynitrite cause calcium efflux from mitochondria which is prevented by cyclosporine A. FEBS Lett 345:237-240

21. Packer MA, Scarlett JL, Martin SW, Murphy MP (1997) Induction of the mitochondrial permeability transition by peroxynitrite. Biochem Soc Trans 25:909-914

22. Pfeiffer S, Gorren AC, Schmidt K, Werner ER, Hansert B, Bohle DS, Mayer B (1997) Metabolic fate of peroxynitrite in aqueous solution. Reaction with nitric oxide and $\mathrm{pH}$ dependent decomposition to nitrite and oxygen in a 2:1 stoichiometry. J Biol Chem 272:3465-3470
23. Pompella A, Cambiaggi C, Dominici S, Paolicchi A, Tongiani R, Comporti M (1996) Single-cell investigation by laser scanning confocal microscopy of cytochemical alterations resulting from extracellular oxidant challenge. Histochem Cell Biol 105:173-178

24. Radi R, Rodriguez M, Castro L, Telleri R (1994) Inhibition of mitochondrial electron transport by peroxynitrite. Arch Biochem Biophys 308:89-95

25. Rakhit R, Crow JP, Lepock JR, Kondejewski LH, Cashman NR, Chakrabartty A (2004) Monomeric Cu,Zn-superoxide dismutase is a common misfolding intermediate in the oxidation models of sporadic and familial amyotrophic lateral sclerosis. J Biol Chem 279:1549915504

26. Shaw PJ, Ince PG, Falkous G, Mantle D (1995) Oxidative damage to protein in sporadic motor neuron disease spinal cord. Ann Neurol 38:691-695

27. Shukla R, Rajani M, Barthwal MK, Srivastava N, Dikshit M (2003) Cerebrospinal fluid nitrite and malondialdehyde levels in patients with motor neuron disease. Int J Neurosci 113:1043-1054

28. Simpson EP, Henry YK, Henkel JS, Smith RG, Appel SH (2004) Increased lipid peroxidation in sera of ALS patients: a potential biomarker of disease burden. Neurology 62:1758-1765

29. Smith RG, Henry YK, Mattson MP, Appel SH (1998) Presence of 4-Hydroxynonenal in Cerebrospinal Fluid of Patients with Sporadic Amyotrophic Lateral Sclerosis. Ann Neurol 44:696699

30. Vielhaber S, Kunz D, Winkler K, Wiedemann FR, Kirches E, Feistner H, Heinze HJ, Elger CE, Schubert W, Kunz WS (2000) Mitochondrial DNA abnormalities in skeletal muscle of patients with sporadic amyotrophic lateral sclerosis. Brain 123:1339-1348

31. Wakai M, Mokuno K, Hashizume Y, Kato K (1994) An immunohistochemical study of the neuronal expression of manganese superoxide dismutase in sporadic amyotrophic lateral sclerosis. Acta Neuropathol (Berl) 88:151-158

32. White RJ, Reinolds IJ (1996) Mitochondrial depolarization in glutamatestimulated neurons: an early signal specific to excitotoxin exposure. J Neurosci 16:5688-5697 
33. Wiedemann FR, Winkler K, Kuznetsov AV, Bartels C, Vielhaber S, Feistner H, Kunz WS (1998) Impairment of mitochondrial function in skeletal muscle of patients with amyotrophic lateral sclerosis. J Neurol Sci 156:65-72
34. Witko-Sarsat V, Friedlander M, Capeillere-Blandin C, Nguyen-Khoa T, Nguyen AT, Zingraff J, Jungers $P$,

Descamps-Latscha B (1996) Advanced oxidation protein products as a novel marker of oxidative stress in uremia. Kidney Int 49:1304-1313
35. Zarkovic K (2003) 4-Hydroxynonenal and neurodegenerative diseases. Mol Aspects Med 24:293-303

36. Zhang J, Dawson VL, Dawson TM, Snyder SH (1994) Nitric oxide activation of poly(ADP-ribose) synthetase in neurotoxicity. Science 263:687-689 